\title{
Music and Culture in Entertainment-Education
}

\author{
Carlos Chirinos-Espin
}

Popular songs have inspired and accompanied social movements and provided a soundtrack to the struggle for social change. In the field of entertainment-education (EE), songs have often been part of interventions to disseminate knowledge and persuade individuals to change behaviors. However, a look at the use of music in entertainment-education suggests that most interventions use music as an additional marketing strategy, rather than a key component.

Entertainment-education centers on the incorporation of "persuasive educational messages" in entertainment programs to increase audience engagement and motivate behavior change (Brown \& Singhal, 1999). From its inception, EE's main goal has been the incorporation of educational messages in entertainment formats to increase knowledge and change attitudes and behaviors to address social issues and advance positive social change.

However, this approach has favored the creation of EE programs guided by Western ideology and values (Dutta, 2008). It frequently

C. Chirinos-Espin, Ph.D. ( $\square)$

NYU Steinhardt and NYU School of Global Public Health, New York, NY, USA e-mail: carlos.chirinos@nyu.edu

(C) The Author(s) 2021

L. B. Frank, P. Falzone (eds.), Entertainment-Education Behind the Scenes, https://doi.org/10.1007/978-3-030-63614-2_8 
imposes a pre-determined agenda on developing countries, often prioritizing health and social issues that do not necessarily reflect the needs and values of the recipient audiences. Televised soap operas, a form of EE that uses drama to engage audiences, have been a very effective way of reaching populations in the developing world, but narratives universalize Western values and norms and neglect social and health priorities of local audiences. Narrative theory posits that stories express identities and make sense of experience through social interaction. Because narratives represent events and characters in an identifiable structure bounded in space and time, they offer a framework for social change communication that distances itself from one-way models of communication (Larkey \& Hecht, 2010). Although EE often bases its strategy on narrative storytelling, when EE interventions are designed without the involvement of local people, they advance the social and economic agendas of powerful groups. In this context, an alternative culture-centered approach posits that the communication process should start from those experiencing the social and health issues in question; the purpose of social change communication-and entertainment-education-should be to enable communication spaces in which social and health issues can be discussed and contested in order to create communication campaigns that are meaningful and relevant to local communities (Dutta, 2008).

Participatory communication departs from the notion that individual and collective engagement in the communication process can activate changes in social norms and opinions around collective decisions. Instead, these changes depend on a social and political context that enables local voices to be heard and encourages critical engagement and consciousness for communities to identify their own problems, generate knowledge, and advance their own priorities and solutions (Chambers, 1997). Through processes that enable local communities to establish their own agendas, participation can help define the communication needs of a community and lead to the creation of culture-centered entertainment campaigns that synthesize information in a format that joins together different levels of thought, feeling, and behavior, and uses cultural references and linguistic diversity to ensure that communication is meaningful and reaches the poorest and most disenfranchised communities.

Participation in music events-songwriting, concerts, contestsenables the public to engage in social actions that require collective learning and coordination. This process facilitates the co-creation and dissemination of songs rooted in culture to make sense of problems and 
articulate solutions. In a context in which traditional music is under threat from dominant forms of commercial music and socio-political control, enabling the creation of songs by marginalized social groups can enable their voices to be heard and counteract the dominant discourses present in other forms of communication. These cultural performances can play a transformative role in raising consciousness and elevating the voices of the socially disenfranchised (Dutta \& Dutta, 2019).

\section{Music-Based Communication}

Music-based communication interventions mobilize individuals for a specific social cause that demands a concerted public action. Music artists create songs that reflect the points of view of those involved. Compared to other forms of EE, music interventions activate cognitive, emotional, empathetic, and culture-centered communication that builds upon three pillars to advance social change: (1) music as a unique form of human communication that resonates with audiences, $(2)$ the celebrity capital of a music artist, and (3) public engagement in music activities.

\section{The Power of Music}

Together with spoken language, music was one of the first human evolutionary traits toward social communication and has significant influence on the biological, psychological, and social factors that determine individual personality and emotional memory (Janata, Tomic, \& Rakowski, 2007). Music performance has been associated with emotional capacity development and with defining psycho-social constructs of personal and social identity (Miranda, 2013). As part of a common language, system of beliefs, and kinship and social structures, music helps define cultural boundaries and provides a shared past that defines values; for example, national anthems provide groups with a unified message that recalls common past, pride, and sense of belonging.

Considering song as a form of spontaneous communication, songs portray the hopes and fears of songwriters and traditional performers who embody the realities of their social environment and reflect popular narrative constructs. Thus, songs may be an appropriate tool to enable communication among communities for whom oral forms of communication are preferred over other forms of communication that do not reflect local identity, language, or values. Some popular songs include narratives with 
important symbolic value that respond to social situations and, by building on music-making as a socially accepted cultural practice, songs can remind community members about health risks and suggest ways to prevent them, particularly when people talk about health narratives in songs (Panter-Brick, Clarke, Lomas, Pinder, \& Lindsay, 2006).

The public appeal of songs reflects their power in articulating shared feelings, emotions, and frustrations. Some music genres (e.g. Hip Hop and Reggae) are cultural forms of resistance that protest political abuse to galvanize public opinions and attitudes. With increased access to music through online streaming services and broadcast radio stations in rural areas with poor internet reception, songs can be considered as a communication capsule that can reach audiences young and old, particularly in multilingual communities. Song repetition increases the likelihood of message exposure in low-literacy contexts; thus, songs may be a subtle and appealing format rather than repetitive orders from authorities about health risks (Bekalu \& Eggermont, 2015).

\section{Celebrity Capital}

As music performers gain media exposure and public attention shifts to their personal lives and opinions, some music artists become music celebrities, and this public attention can be used to mobilize the public for social action. Celebrity capital refers to media visibility and the resulting power that can be used to benefit products, causes, and institutions (Driessens, 2013). Social cognitive theory suggests that identification defines the process in which individuals build special links with others, imitate their lifestyle, follow their verbal guidance, and adopt their behaviors and values, and this perceived relationship can lead to opinion change (Bandura, 2002). Thus, the relationship between music celebrities and fans over time builds emotional connections and trust. Moreover, source credibility theory posits that the credibility of information depends on the perceived trustworthiness and expertise of the information source (Hovland \& Weiss, 1951). Individuals may identify with celebrities and trust them, establishing a parasocial relationship with them, a process in which audiences have the illusion of intimacy with a celebrity (Fraser \& Brown, 2002; Horton \& Wohl, 1956). As celebrities share personal experiences and support for social causes, fans perceive that supporting those causes satisfies the celebrities' wishes, and this can persuade fans to change their opinions and advocate that others change. 


\section{Public Engagement in Music Activities}

Music events that enable collaboration between artists, fans, and development and health actors can stimulate the development of critical thinking, collaboration, and empowerment that Freire defined as a 'problem-posing' approach to education (Freire, 1970). By involving artists and audiences in dialogue and mutual learning, music-based interventions can enable local voices to be heard, contribute to collective empowerment, and help communities define their goals and priorities. Through collaborative songwriting and other forms of celebrity activism, music-based interventions can enable co-creation of messages that are defined by the needs and knowledge of groups seeking social change. In this process, community engagement is mediated through the identification of fans with the musical output, the personality, the values, and opinions of music celebrities. This relationship provides the conditions for the public to engage in dialogue that may lead to opinion and behavior change. In the context of historical, political, and social divisions in culturally heterogeneous societies-as is the case in many low- and middle-income countries-music celebrities with a strong fan base may have the ability to translate and disseminate information, as they help translate complex ideas to simple stories in song. Music celebrities are recognized opinion makers who can mobilize the public through their songs and their activism for social change (Pratt, 2009). Through a combination of participation of local music artists and public engagement, music presents an alternative form of entertainment-education to dominant forms of EE that replicate Western values and behavioral models that are not rooted in local culture (Dutta \& Dutta, 2019).

\section{Africa Stop Ebola}

To contextualize these ideas, I will discuss my work on Africa Stop Ebola (ASE), an entertainment-education intervention that engaged a collective of West African music artists to create a song to promote community engagement in response to the Ebola epidemic in West Africa. Led by the Ivorian reggae artist Tiken Jah Fakoly and featuring the artists Amadou and Mariam, Salif Keita, Oumou Sangare, Sia Tolno, Barbara Kanam, Mory Kanté, Mokobé, Markus, Didier Awadi, and Kandia Kora, I contributed as a co-writer and co-producer of the song. The song was created as a collaborative composition in which I played the role of facilitator and 
researcher. As a facilitator, I investigated the key factors in social resistance to Ebola in Guinea, created a list of "topics" to address in the song, and worked in the studio with the music artists to record and edit the verses of each of the 12 performers.

Based on reports about Ebola that indicated public mistrust in health workers and a general loss of public hope in finding a solution to Ebola, we identified these key messages as the main subjects to be addressed in the song. Therefore, the song's goal was to communicate two main topics: first, to persuade individuals to trust the health workers responding to the crisis, and second, to encourage hope that the crisis could be overcome. The song also included behavioral commands like "don't touch the sick, don't touch the dead" and "avoid shaking hands and be safe" to promote preventive behaviors. Through the verses, the song intended to serve as a nudge to remind listeners about the importance of listening to health actors involved in the response to the epidemic. We encouraged each artist to write an eight-bar verse in their own preferred language that addressed or emphasized these two key concepts. The resulting song included verses performed in French, Malinké, Soussou, Banbara, and Lingala, and the choruses "Ebola, invisible enemy" and "Ebola, trust the doctors." The song was released as a music video (Fakoly et al., 2014) and was reported in the international media as a positive strategy to promote Ebola prevention in West Africa (Jones, 2014; Kozin, 2014).

\section{Africa Stop Ebola Song Lyrics}

Africa is sad, to see our families die. Do not touch our sick; do not touch the dying; Everyone is in danger, Young and old, we must act for our families

Chorus: Ebola, Invisible Ebola Invisible

Ebola you are our enemy, If you feel sick the doctors will help you, I can assure you, the doctors will help you, and there is hope to stop Ebola, trust the doctors

Chorus: Ebola, Ebola, Trust doctors

Ebola it's not good, go see the doctor, Ebola it's not good, go see the doctor, Ebola hurt you must see the doctor, Ebola it's not good, go see the doctor

\section{Chorus}

Take Ebola seriously. It is a very serious disease. When she reaches you, death follows. As soon as you have the symptoms, send for the doctors. 
They can help you. Wash your hands regularly and avoid shaking hands with others.

I beg you dear parents, let's follow the advice of the medical authorities, Ebola came to hurt us, Let's respect their advice.

Ebola you kill our people, you add pain to the DRC (Democratic Republic of Congo), but we will defeat you, let's remain standing.

Get up, get up, Ebola is a problem for us, we cannot greet someone, we cannot kiss someone, It does not mean that person shames you, it's just a reality

Ebola has become a problem for us today, I ask all doctors in Africa to get up, Ebola really became a problem for us

\section{Chorus}

Once again we talk about tragedy, like a false note that comes in the melody, Ebola we thought you were since abolished, you walk in the debauchery sowing disease, we will not run away from you we will not bury ourselves, because we know we have ways to get away, we're going to get hooked we're not plague, we're going to get together, we will fire you!

Among them there are many who have been able to access hospitals, those who are cured are no longer contagious, there are some who stay at home until the evil grows, Oh my God! Mama Africa get up and stay united as we are used to doing for our other battles, Ebola you will also be defeated

Another drama that hits the continent, Africa needs vaccine and medicine, is hope for them allowed? Is it necessary to close our eyes and leave them in oblivion? (no!) So we unite for a good cause, we mobilize, we break the closed doors, Ebola I swear to chase you until you leave, Africa needs the vaccine to heal.

\section{Chorus}

The promotion of the song in the international media led to a strategic association with the medical humanitarian organization Médecins Sans Frontieres (MSF France); they used the song and the image of the ASE artist collective in their awareness campaign and fundraising efforts to combat Ebola in West Africa. As a result, the campaign was nominated to Fighting Ebola: A Grand Challenge for Development, an innovation award that provided resources to implement an intervention in the form of a song contest in Conakry, Guinea (USAID, 2015). 
I worked with collaborators to create a participatory communication intervention in the form of a song contest to engage local artists in Conakry, Guinea, to create songs to promote Ebola prevention. To promote the song contest and recruit local artists, we implemented a social marketing campaign with TV and radio ads, posters, leaflets, and social media posts. Over 250 local artists auditioned, out of which 14 were selected to participate in workshops with health promotion workers and music coaches to enable them to write original songs about Ebola. Through this process, local artists were able to talk with health workers such that both parties articulated their ideas and expressed their opinions. Yet the final lyrical content of the songs was created by the artists and included diverse points of view and diverse music genres (e.g. gospel, reggae, traditional music, and Afro-pop). To conclude the intervention and select a group of winners of the song contest, we organized a final public event that was recorded for TV broadcast and online streaming, in which artists performed their songs and spoke about their personal experiences with Ebola (Africa Stop Ebola, 2015). The public event was hosted by the artists Tiken Jah Fakoly and Mory Kanté, both considered international music celebrities with a strong cultural connection to Guinea.

The affiliation of the song contest with the local office of MSF may have helped improve the image of health workers with the local communities through a process of negotiating reciprocity and trust with local music artists who represented civil society, helping break the barrier between health institutions and civilians. The workshops and collaborations with other artists and health workers to write the lyrics of the songs created a genuine process of engagement that helped local artists better understand the social and behavioral challenges of Ebola prevention. In this regard, the process of the song contest was more important than the resulting songs since it created a space for dialogue, self-expression, and knowledge generation. The resulting songs provided a narrative about Ebola prevention from the point of view of the communities affected. Many of the resulting songs reinforced trust in the health sector and avoidance of contact with others, which were to a great extent, narratives promoted by health actors as well. However, the manner in which the songs appealed to the public started from local culture to make sense of the crisis and encourage the public to prevent the disease.

In this intervention I applied an action research methodology in which I became a facilitator of a process of dialogue between local music artists and some of the health workers responding to the crisis. I documented 
events in audiovisual format, conducted a knowledge, attitudes, and practices survey of the general public, and carried out interviews with health workers to understand the impact of the intervention in Ebola prevention (Chirinos-Espin, 2019). Through this process, I learned that social resistance to social interventions to control Ebola was the result of previous negative experiences with ruling political parties and medical interventions in West Africa. In the context of a medical emergency caused by an unknown infectious disease like Ebola, my findings suggested that music artists may be in a better position to communicate with civil society than institutional actors because they are trusted by the public and are able to communicate complex biomedical information in appealing stories. The source credibility model provides a theoretical basis to explain this, as it suggests that the trustworthiness of the information source does not affect the acquisition or retention of information, but it significantly influences opinion change (Hovland \& Weiss, 1951). For example, evidence of the effectiveness of spokespersons in public service announcements suggests that people pay less attention to messages when delivered by international celebrities because they lack a direct connection to the crisis or are doing it for their own image, but people pay more attention and are motivated to change their opinion when a local person delivers the message because of a sense of belonging to the same place and identifying with them (Toncar, Reid, \& Anderson, 2007).

The involvement of local artists in the songs and the public broadcast of the contest on radio, TV, and online enhanced the perception of local ownership of the message and enabled emotional engagement. In the vacuum of professional journalism and constraints imposed on the media by governments or private commercial interests in Africa, music is a tool for emancipation of youth that reflects the everyday experiences of people in the peripheries; lyrics often represent the everyday concerns of ordinary people (Mano, 2007).

The original ASE song was produced in the style of reggae, a music genre that is part of a legacy of social activism as a pan-African music genre associated with critique of racism and imperialism. Reggae represents an avenue for self-expression and dissent that challenges the status quo and enables the voice of youth in Africa, disenfranchised by poor job opportunities and political oppression, to contest dominant narratives and call out abuse of power by local and global elites (Reed, 2012). Thus, even though the lyrics of the song addressed trust and hope, reggae suggested a connection of the crisis with the imbalances of global political power. In this 
sense, collective song creation allows communities to interpret a social phenomenon, create and share collaborative knowledge, and appeal to youth and collectivist societies that value music as an endogenous form of cultural expression.

\section{Music in the Time of COVID-19}

As I write the final pages of this chapter, the world is going through a crisis related to the COVID-19 pandemic. From singers serenading neighbors from Italian balconies to songs about washing hands, music played an important role in sharing information, hope, and stress relief during the first months of 2020. Through songs, performances, and actions, music artists activated their fans to advocate for public health. One of the songs produced during the early stages of the pandemic provides an example of how music may be a useful tool in youth engagement in COVID-19 prevention. Vietnam is credited for reacting to the early warnings of the outbreak in Wuhan, China, by implementing social distancing rules, border closures, and contact tracing early on. Having had previous experiences with outbreaks of infectious diseases and knowing the potential effects of an uncontrolled epidemic on the health care system, the country opted for a policy of prevention that contributed to containing cases (Jones, 2020). Early on in the COVID-19 pandemic, Ghen Cô Vyl NIOEH x K.HỦNG $x$ MIN x ERIK (2020) collaborated with the Ministry of Health, Vietnam, and Vietnam's National Institute of Occupational and Environmental Health to release the washing hand song on YouTube. At the time of writing, this song has been watched over 53 million times. Its lyrics urge listeners to stay alert, avoid touching their face, and maintain social distance. The video became popular on social media, and a user created a choreographed video on TikTok - an emerging popular social media channel for user-generated videos-that inspired many others to copy it. The TikTok featured young Vietnamese choreographer Quang Dang performing the handwashing challenge and shows handwashing steps coordinated with the song and tagged with the hashtags \#vudieuruatay \#handwashingmove (Đang, 2020). Using the song as a time cue for length and coordination, the choreography shows the appropriate steps to wash hands, helps users remember the steps to wash hands thoroughly, and provides persuasion through peer-to-peer influence in the form of millions of users who responded to the online challenge, copied the choreography, and posted it online. 
Another form of social mobilization through music was the activism of artists who rallied to fundraise for the World Health Organization (WHO) and promote COVID-19 prevention. In April 2020, American artist Lady Gaga launched "One World Together at Home," a virtual concert that featured an all-star line-up of celebrity music artists who performed and asked viewers to stay home and donate to the WHO. The concert was endorsed by Director-General of the WHO, Dr. Tedros Adhanom Ghebreyesus (World Health Organization, April 18, 2020). It provided a platform for artists to perform, at a time when all live music events were canceled, and to show their support for WHO and actions to stop the spread of COVID-19. During the show, artists promoted a positive attitude toward the WHO, although the official US narrative partially blamed the WHO for a slow response to COVID-19. Through celebrity involvement, the public mobilized to make donations, which confirmed that the public agreed with the message. In these two COVID-19 examples, song and celebrity capital enabled public engagement through user-generated videos and contributing funds to support a global institution working on COVID-19 relief, which further supports that popular music can be an effective social mobilization tool.

\section{Lessons Learned and Best Practices}

Through the Africa Stop Ebola project in Guinea, we implemented an entertainment-education campaign that relied on song to engage local people in creating and disseminating health information in a manner that connected with the needs of the local people. In this process, the initial idea of creating a "health education" message in a song changed to a message that encouraged listeners to trust the response and have hope that the epidemic could be stopped. The artists were more confident about delivering messages of wisdom and hope than repeating the normative messages about disease prevention disseminated by health actors in the region (avoiding touching and social distancing); the project focused on addressing the collective emotional toll of the health crisis and responded to the artists' own views. This highlights a key lesson: local artists are the most able to create content that resonates with their communities. Following the principle of using entertainment-education to reach the poorest and most disenfranchised communities, we used Reggae and local forms of Hip Hop to create a popular song. 
We learned to prioritize media that was accessible by those living in rural and remote areas who are often isolated and neglected in the communication process as a result of their culture, language, or size of their community. This included a free digital music video on YouTube and promotion on local radio stations. The use of radio helped to reach communities with diverse languages, since radio stations enable many indigenous and rural communities living in extreme poverty to access information and communication in their own languages via simple battery-operated radios. Radio provides a reliable tool to reach disenfranchised rural groups that do not have access to broadcast TV, digital, or written communication.

One of the biggest challenges to music-based EE interventions is conducting monitoring and evaluation as interventions occur. Since funding for EE interventions is tied to the ability to produce evidence of effectiveness, planning a monitoring and evaluation protocol in advance was a critical step to ensure that we could collect data to understand potential impact. To evaluate the intervention, I collected media metrics such as number of views of the online music video, the number and type of users' comments, and press coverage of the song in the international and local press in Guinea. I conducted surveys inquiring into the public perceptions of the effectiveness of songs and music artists in communicating about Ebola. The results showed that music artists were perceived as trusted sources of information about health, and that songs were perceived as an effective way to communicate with young people. I also interviewed health workers and MSF health promotion managers, and I found they valued the intervention as it provided a novel method to communicate and engage people in a context of public fatigue with Ebola messages. This was another important lesson learned: the communication environment during a health crisis can become overloaded with repetitive messages that demand behavior change from individuals without consideration of their emotional impact. Repetition leads to public fatigue, which can negatively impact efforts to control a disease. In this sense, what started as a health communication campaign ended as an emotional communicational tool created by artists to promote trust and hope in the context of a high level of public mistrust in state and international development actors.

The effectiveness of this process goes beyond the social marketing value of songs as vehicles for message dissemination because music enables the creation of culture-centered narratives that can engage the public in dialogue and critical reflection. Thus, music in entertainment-education provides a platform for bottom-up community engagement in actions to address social change and health communication through participatory communication. 


\section{REFERENCES}

Africa Stop Ebola. (2015). Africa Stop Ebola song contest in Guinee. Retrieved from https://www.youtube.com/watch?v=itlpFxjxeIs

Bandura, A. (2002). Social cognitive theory of mass communication. In J. Bryant \& D. Zillmann (Eds.), Media effects: Advances in theory and research (pp. 121-153). Erlbaum.

Bekalu, M. A., \& Eggermont, S. (2015). Aligning HIV/AIDS communication with the oral tradition of Africans: A theory-based content analysis of songs' potential in prevention efforts. Health Communication, 30(5), 441-450.

Brown, W. J., \& Singhal, A. (1999). Entertainment-education media strategies for social change: Promises and problems. In D. Demers \& K. Viswanath (Eds.), Mass media, social control, and social change: A macrosocial perspective. Iowa State University Press.

Chambers, R. (1997). Whose reality counts? Putting the last first. Intermediate Technology Publications.

Chirinos-Espin, C. (2019). Africa Stop Ebola: Social resistance and music-based participatory communication in Guinea's Ebola Epidemic 2014-15[Unpublished Doctoral thesis]. SOAS, University of London.

Đang, Q. (2020). Handwash choreography. TikTok. Retrieved from https://www. tiktok.com/@im.quangdang/video/6795172608770870529

Driessens, O. (2013). Celebrity capital: Redefining celebrity using field theory. Theory and Society, 42(5), 543-560. https://doi.org/10.1007/s11186-013-9202-3

Dutta, M. J. (2008). Communicating health: A culture-centered approach. John Wiley \& Sons.

Dutta, U., \& Dutta, M. J. (2019). Songs of the Bauls: Voices from the margins as transformative infrastructures. Religion, 10(5), 335.

Fakoly, T., Keita, S., Sangare, O., Amadou \& Mariam, Kanté, M., Kanam, B., Tolno, S., Mokobé, Markus, Awadi, D., \& Kandia Kora. (2014). Africa Stop Ebola. YouTube. Retrieved from https://www.youtube.com/ watch?v=ruYQY6z3mV8\&ab_channel=AfricaStopEbola

Fraser, B. P., \& Brown, W. J. (2002). Media, celebrities, and social influence: Identification with Elvis Presley. Mass Communication and Society, 5(2), 207-228. https://doi.org/10.1207/S15327825MCS050

Freire, P. (1970). Pedagogy of the oppressed. 30th Anniversary Edition. Continuum. Ghen Cô Vyl NIOEH x K.HUNG x MIN x ERIK. (2020). Washing hand song, Corona song. Retrieved from https://www.youtube.com/watch?v= BtulL3oArQw\&feature $=$ emb_logo

Horton, D., \& Wohl, R. (1956). Mass communication and parasocial interaction: Observations on intimacy at a distance. Psychiatry, 19, 215-229.

Hovland, C. I., \& Weiss, W. (1951). The influence of source credibility on communication effectiveness. The Public Opinion Quarterly, 15(4), 635-650. 
Janata, P., Tomic, S. T., \& Rakowski, S. K. (2007). Characterisation of musicevoked autobiographical memories. Memory, 15(8), 845-860. https://doi. org/10.1080/09658210701734593

Jones, A. (2020). Coronavirus: How "overreaction" made Vietnam a virus success. $B B C$ News. Retrieved from https://www.bbc.com/news/world-asia-52628283

Jones, S. (2014). African musicians band together to raise Ebola awareness. The Guardian Global Development. Retrieved from https://www.theguardian. com/global-development/2014/oct/29/african-musicians-recordsong-ebola-awareness

Kozin, A. (2014). How to protect yourself from ebola, in song. The New York Times. Retrieved from https://artsbeat.blogs.nytimes.com/2014/10/29/ how-to-protect-yourself-from-ebola-in-song/

Larkey, L. K., \& Hecht, M. (2010). A model of effects of narrative as culturecentric health promotion. Journal of Health Communication, 15(2), 114-135.

Mano, W. (2007). Popular music as journalism in Zimbabwe. Journalism Studies, $8(1), 61-78$.

Miranda, D. (2013). The role of music in adolescent development: Much more than the same old song. International Journal of Adolescence and Youth, 18(1), 5-22. https://doi.org/10.1080/02673843.2011.650182

Panter-Brick, C., Clarke, S. E., Lomas, H., Pinder, M., \& Lindsay, S. W. (2006). Culturally compelling strategies for behaviour change: A social ecology model and case study in malaria prevention. Social Science \& Medicine, 62(11), $2810-2825$.

Pratt, C. B. (2009). Using the personal influence model to guide theory building for participatory communication in Africa. Communicatio: South African Journal for Communication Theory and Research, 35(1), 30-49.

Reed, D. B. (2012). Promises of the chameleon: Reggae artist Tiken Jah Fakoly's intertextual contestation of power in Côte d'Ivoire. In E. Charry (Ed.), Hip Hop Africa: New African music in a globalizing world (pp. 92-108). Indiana University Press.

Toncar, M., Reid, J. S., \& Anderson, C. E. (2007). Effective spokespersons in a public service announcement: National celebrities, local celebrities and victims. Journal of Communication Management, 11(3), 258-275.

USAID. (2015). United States announces additional results in Grand challenge to fight Ebola. USAID. Retrieved from http://www.usaid.gov/news-information/ press-releases/feb-11-2015-united-states-announces-additional-resultsgrand-challenge-fight-ebola

World Health Organization. (2020). 'One world: together at home' global special. Retrieved from https://www.who.int/news-room/events/detail/2020/04/18/ default-calendar/one-world-together-at-home-global-special 
Open Access This chapter is licensed under the terms of the Creative Commons Attribution-NonCommercial-NoDerivatives 4.0 International License (http:// creativecommons.org/licenses/by-nc-nd/4.0/), which permits any noncommercial use, sharing, distribution and reproduction in any medium or format, as long as you give appropriate credit to the original author(s) and the source, provide a link to the Creative Commons licence and indicate if you modified the licensed material. You do not have permission under this licence to share adapted material derived from this chapter or parts of it.

The images or other third party material in this chapter are included in the chapter's Creative Commons licence, unless indicated otherwise in a credit line to the material. If material is not included in the chapter's Creative Commons licence and your intended use is not permitted by statutory regulation or exceeds the permitted use, you will need to obtain permission directly from the copyright holder. 